\title{
An Important Milestone in Parasitology: Celebrating a Hundred Volumes of Advances in Parasitology
}

\author{
J. Russell Stothard ${ }^{1}$ and David Rollinson ${ }^{2}$ \\ ${ }^{1}$ Department of Parasitology, Liverpool School of Tropical Medicine, Pembroke Place, \\ Liverpool, L3 5QA, UK; \\ 2 Department of Life Sciences, Natural History Museum, Cromwell Road, London, SW7 5BD, \\ UK;
}

\section{Abstract}

1. Introduction

1.1 An important milestone to celebrate

2. Maintaining the tradition through time

2.1 Profiles of the editors

2.2 Synopsis of production

3. Reflections on content and influence

3.1 Volume 1

3.2 Volume 50

4. Does parasitology still need Advances in Parasitology?

5. Outlook

References

\section{ABSTRACT}

Beginning in 1963, the founding rationale of Advances in Parasitology was to provide authentic, well-documented reviews by leading experts, about the progress being made in their area of specialism to inform the wider cadre of parasitologists, disseminating this information across allied disciplines and all users. Some 55 years later, the Series has accumulated over 667 published articles, with just over 650 authors contributing either alone or in collaboration, and has successfully served the parasitological needs of medical, veterinary and wildlife scientific communities with equity; notwithstanding treatises on vectors or intermediate hosts, as well as 'honorary parasites' such as viruses, bacteria and fungi. The first production of Advances in Parasitology united the publishing offices of Academic Press in the USA (New York) and the UK (London), maintaining Webster or Oxford 
writing styles, but unlike its production, all seven editors, beginning with Professor Ben Dawes, have been UK-based. While Advances in Parasitology is now published by Elsevier from their London Office, it still follows the tradition of hard backed book production, in either eclectic or thematic volume formats. But now, following academic imperatives, the Series supports online posting, allowing chapter(s) to be downloaded ahead of final production of the hard back volume. With the $100^{\text {th }}$ volume of Advances in Parasitology, in eclectic format like the very first, there is good reason to celebrate and reflect on the academic impact and enduring legacy of this Series. Seen not only as a yardstick of publishing success but also as a testament, in part, to our fascination with parasites, these cursorily simple yet wonderfully complex organisms that often cause undue harm and much suffering, is still as vibrant, expanding and relevant as ever before.

Keywords: helminthology, protozoology, historical appraisal, bibliometrics, Advances in Parasitology

\section{Introduction}

The Series Advances in Parasitology was founded in 1963, and has established a long tradition of commissioning and publishing invited reviews that advance the discipline of parasitology in the widest sense (Dawes, 1963). Over the past 55 years, there has been an unbroken chain of production of volumes year on year of either eclectic or thematic nature. As a collection, they each serve the interests of all those interested in parasitology, either occasionally or continuously, of both professionals, students and amateurs. In 2018, the $100^{\text {th }}$ edition of Advances in Parasitology will be produced; therefore, there is good reason to celebrate this occasion with a look back at the past but also to prepare for the future. Looking backwards, we can applaud the achievement of over 667 articles published from just over 650 authors, especially as these have equitably served the parasitological needs and interests of medical, veterinary and wildlife scientific communities throughout the world. Furthermore and broadening the scope of parasitology, there have also been important treatises on parasite vectors and intermediate hosts, as well as occasional exploratory forays into the world of 'honorary parasites' such as viruses, bacteria and fungi, see Figure 1. 
<insert Figure 1 near here please>

The ambition for this article is threefold. First, the chapter serves as a preface to the $100^{\text {th }}$ volume and shows how the most recent volume echoes the ethos of the first and fiftieth volumes. Second, we seek to record a bibliometric history of the journal, demonstrate its publication successes with associated measures of impact; we acknowledge the dedication of editorial and production teams (past and present). We also thank our thematic guest editors and editorial boards who have brought their expertise to bear, all of which has deepened the vision and scope of Advances in Parasitology both in succession planning and fresh expertise. Finally, we aim to highlight, in part, our deeper fascination with parasites to identify research trends through time. Parasites are typically small and cursorily simple organisms, yet have evolved wonderfully complex strategies and life histories. They often have a pernicious motive and tenacious capacity to cause their hosts much harm and suffering. We therefore conclude our celebratory chapter by posing the simple question 'does parasitology still need Advances in Parasitology?' We still believe so.

\subsection{An important milestone to celebrate}

As per the very first and fiftieth volume of Advances in Parasitology (see below), the $100^{\text {th }}$ edition follows an eclectic form with 8 invited chapters. The first four chapters are firmly embedded in medical parasitology, but with each having a forward-looking perspective. We are especially delighted to welcome Peter Hotez's contribution (Hotez, 2018). Despite not being a review in the strictest sense, it is a prophetic opinion and treatise on the future importance of parasites and their diseases and is set against the growing urbanisation of the human populace (Hotez, 2018). Whilst there are real prospects to reduce and eliminate certain parasitic diseases, several neglected tropical diseases in particular, there are also reasons for concern and pessimism. Foremost, further spread of the anti-science lobby is hampering many efforts in public health, especially in the USA, such as vaccination, and elsewhere with preventive chemotherapy campaigns (Hotez, 2017). Mitigating these detrimental trends will be challenging, but with better scientific communication and dissemination of appropriate evidence to the right stakeholders and ensuring a better- 
informed populace, these hurdles may be overcome. In line with universal health coverage, having a responsive health system, seen to benefit all, is essential (Hotez, 2018).

The theme of neglected tropical diseases is further developed by Mark Booth, being discussed in relation to expected climate change and its uncertainties (Booth, 2018). It is well known that climate change will have both direct and indirect impacts upon many of the sustainable development goals (SDG) and their indicators; especially those that are known to exacerbate poverty, for example, through ill-health and failure to thrive. The aetiological agents or pathogens responsible for 34 infections (i.e. viruses, bacteria, fungi, protists and helminths) now grouped within the neglected tropical disease umbrella are diverse, notwithstanding snake envenoming or podoconiosis. Like those of parasitic aetiology, they are all sensitive to environmental change, some more than others, so it may be difficult to predict precisely the direction of change for each disease or those in combination. Booth (2018) discusses their transmission dynamics and endemic areas, either known or putative, to speculate whether these afflictions may be enhanced or diminished, framing these changes over short (seasonal), medium (annual) and long (decadal) term perspectives.

The progress in improving child development in resource-poor settings is discussed by Don Bundy and set within the broader context of intervention strategies that reduce parasitic infection and increase childhood nutrition (Bundy, 2018). It is known that the first 1000 days of childhood, children are particularly vulnerable to parasitic insult and, as a consequence, are particularly sensitive to growth faltering and cognitive impairment (Bundy et al., 2018), all of which could be avoided. Therefore, in terms of appropriate investment(s), interventions need to be targeted and adaptive through time to ensure that such unfortunate children have a better chance in life and the best chance for catch-up growth. Furthermore, these interventions also broaden and transition into psychosocial support systems to ensure children can attain the best level of development and social engagement alongside more robust emotional control.

Taking a more parasite-focused food-borne trematode perspective, clonorchiasis is a significant neglected tropical disease in Asia. It blights the lives of millions locally, largely due to the trematode infection triggering carcinogenic processes that ultimately result in fatal cholangiocarcinoma. The chapter by Darcy Wanga et al. (2018) provides an update on understanding the genetic diversity of Clonorchis sinensis and undertakes a molecular comparison of sequence divergence within key nuclear and mitochondrial genes (Wanga et 
al., 2018). Furthermore, with advances in genomics and bioinformatics there is now ample opportunity to compare the biochemical pathways of flukes and identify novel biomarkers from closely-related species to help develop new fluke-specific intervention targets.

With reference to another trematode disease, schistosomiasis, Renata Candido et al. (2018) provide a review on the bio-physical properties of eggs of Schistosoma with specific regard to biomagnetic properties of the egg shell itself. This unusual feature of the egg can be taken advantage of to develop novel diagnostics or better methods to concentrate and trap eggs for enumeration (Candido et al., 2018). Advancing and adapting such new technologies to harvest eggs from body fluids could offer a low-cost solution to current diagnostic bottlenecks for disease surveillance and monitoring of schistosomiasis.

The final chapter in this eclectic volume by Alejandro Trujillo- González et al., addresses a much overlooked aspect in aquatic parasitology, the movement of ornamental fish stocks and with it the translocation of populations of parasite assemblages into previously non-endemic areas (Trujillo-González et al., 2018). A cornerstone fish species in the ornamental trade is the Goldfish (Carassius auratus). Whilst this fish gives us much atheistic pleasure and has been valued extremely highly in some cultures, it has been traded for over 500 years in over 100 countries. In total, more than 113 species of parasite, inclusive of helminth and protists, infect goldfish within their native range but just under a quarter of these are known to have co-invaded new environments with international trade. Future attention to biosecurity, management and cross-border detection methods is needed if the spread of exotic parasites from the ornamental trade of goldfish is to be curtailed. Like climate change, it is difficult to predict the consequences of invasive parasitic species and anthropogenic-induced change, but it is essential that biosecurity should be tightened and improved to best prepare for the future.

\section{Maintaining the tradition through time}

In total, there have been seven editors of Advances in Parasitology with variable periods in post, either singularly or working within a team. Here, we provide a short synopsis to sketch a picture of their interests in parasitology and their place within this journal through time. Despite Advances in Parasitology's USA and international connections, all editors have been UK-based with diverse careers and technical skills and have focused on different specialist areas within parasitology. Indeed, there is a veritable $A$ to $Z$ of multidisciplinary skills 
spanning from anatomy (e.g. Ben Dawes and embryology) to zoonosis (e.g. Russell Stothard and zoonotic schistosomiasis) with much in between. Each has guided, individually or in combination, the scope and content of this journal, alongside the production team, with a passion, enthusiasm and dedication equal to that of their fascination with their chosen parasite.

Beginning with the first editor, Professor Ben Dawes from King's College London, the journal was first published by Academic Press, uniting their offices in New York and London and maintained Webster or Oxford writing styles for USA- or UK-affiliated authors, respectively. Academic Press was originally an independent publishing house, but was later acquired by Harcourt, Brace \& World in 1969. Today, Advances in Parasitology is published by Elsevier from their London Office, alongside a recent change of production staff with Ana Claudia Garcia as Editorial Project Manager and Ashlie Jackman-Juler as Acquisition Editor of Elsevier Serials and Handbooks. It still follows the tradition of hard back book production, in either eclectic or thematic chapter formats, but now following the academic imperative of rapid publication, has advance online posting which allows access to each chapter(s) ahead of hardcopy production. The journal, which can also be viewed as a book serial, has in recent years maintained an attractive impact factor, citation half-life and has been consistently placed in the first quartile of parasitological journals, a testament to the quality and production of its manuscripts. For example, in the 1998-2017 period there have been 486 publications, with a citation average of just under 50 per article.

\subsection{Profiles of the editors}

Ben Dawes b. 1902 - d. 1976 (1963-1976, Volumes 1-15) was the founding editor of Advances in Parasitology and led the journal single handed, volume by volume in step with each year, until his death when still preparing production of volume 15 . He was born in Burnley and although performed excellently at school, went to work then aged 12 in the Lancashire weaving mills. There, he was to learn a tough work ethic which stayed with him throughout his life and it was only after receiving a national studentship did he go on to study zoology at Royal College of Science (now Imperial College London) in 1924. Subsequently, his career in academia blossomed; he undertook seminal studies in anatomy, embryology and developmental biology, later becoming an eminent parasitologist and 
Professor of Zoology at King's College London. It was said that Ben knew or came to know each of the journal's contributors personally, and often spoke with admiration and respect for the learning and efforts of others. He considered Advances in Parasitology a great fund of up-to-date information of prodigious value in veterinary and medical sciences, as well as biology in general.

W.H. Russell Lumsden b. 1914 - d. 2002 (1976 - 1982, Volumes 16-20) initially qualified as a zoologist at Glasgow University in 1935 and after matriculating in medicine graduated in 1938. He had a varied career and saw military service during 1939-1945 in the British Army as commanding officer of No. 3 Malaria Field Laboratory. He later specialised in virology and undertook seminal work in Uganda joining the Yellow Fever Research Institute in Entebbe (now Uganda Virus Research Institute, today part of the London School of Hygiene \& Tropical Medicine) before directing the East African Trypanosomiasis Research Organization. In Uganda, he turned his attention on kinetoplastids and the trypanosomes. After returning to the UK and working at Edinburgh University, in 1968 he took up a Chair in Medical Protozoology at the London School of Hygiene \& Tropical Medicine. He co-wrote with W.J. Herbert and G.J.C. McNeillage Techniques with trypanosomes (Churchill Livingstone, 1973) and edited with David Evans the key two-volume text Biology of the Kinetoplastida (Academic Press, 1976-1979). Upon the death of Ben Dawes, Russell was asked to provide stewardship of the journal. This he did and to ensure longer term succession planning, he recruited John Baker and Ralph Muller to the editorial team to oversee protozoology and helminthology, respectively.

John R. Baker b. 1931 - d. 2013 (1978 - 2006, Volumes 16-64) was co-editor with Ralph Muller and an eminent protozoologist, with particular interest in Trypanosoma. John obtained his PhD under the supervision of Professor P.C.C. Garnham FRS and went on to spend some time working in Tororo, Uganda with the East African Trypanosomiasis Research Organisation. He later undertook key work in South-East Ethiopia on the epidemiology of sleeping sickness with the US Naval Medical Research Unit (NAMRU-3) based in Addis Ababa. John authored several text books with three being particularly influential, Parasitic Protozoa (1969), Medical Parasitology (1989), co-authored with Ralph Muller and The Biology of Parasitic Protozoa (1982). John was one of the founding members of the British Society of Parasitology (BSP) being the first General Secretary from 1962- 
1965. During the late 1980s, he led the British section of the Society of Protozoologists, and for a short while was also editor of Parasitology Today.

Ralph Muller b. 1933 - d. 2007 (1978 - 2007, Volumes 16-65) was co-editor with John Baker for almost thirty years continuing on until shortly before his death. Ralph was one of the foremost helminthologists of the twentieth century in the UK, an international expert on dracunculiasis and many other medical helminths. Beginning his life's work as a parasitologist in 1955, when he graduated in zoology from Queen Mary College (University of London), he worked in Africa with the Overseas Development Administration then in 1966, he joined the Department of Parasitology of the London School of Hygiene and Tropical Medicine, where he published many studies on Guinea worm and was involved in its control. Whilst there and two years after the death of Ben Dawes, Ralph assisted Professor Russell Lumsden oversee Advances in Parasitology. He continued on for a further 15 years at the London School before leaving to become the Director of the International Institute of Parasitology in St Albans in 1981, remaining there until 1993 and retirement. Ralph is perhaps best remembered as author of two very influential text books Worms and Disease: A Manual of Medical Helminthology (William Heinemann, 1975) and Medical Parasitology, with John Baker as co-author (J. P. Lippincott Company/Gower Medical Publishing, 1990). He and John were great friends, working as a pair, before inviting David Rollinson onto the editorial team.

David Rollinson (1994 - present, Volumes 34-100) is a Merit Research Scientist at the Natural History Museum in London, where he leads a research team in the Wolfson Wellcome Biomedical Laboratories and directs the WHO Collaborating Centre for schistosomiasis. In 2017, David became Director of the Global Schistosomiasis Alliance and has devoted much time and energy to disease control in the tropics, spanning from the highest levels of WHO and policy to on-the-ground with community health volunteers. David has had a long fascination with parasites and the diseases that they cause, and this has involved him in many overseas projects especially in sub-Saharan Africa. David is on the WHO Expert Advisory Panel of parasitic diseases, the senior editor of Advances in Parasitology and a former President of the World Federation of Parasitologists and British Society for Parasitology. David's research group uses a multidisciplinary approach, which combines detailed molecular studies in the laboratory with ongoing collaborative studies in endemic areas of disease, to explore the intriguing world of parasites in order to help 
control and eliminate parasitic diseases. David has received many honours and awards in recognition of his considerable contribution to the field of parasitology. For over a decade, Advances in Parasitology was published from an editorial team of 3 which worked for many years until retirement of John Baker. David innovated the journal's production with introduction of thematic issues alongside secondment of guest editors to bring their specialist knowledge temporarily to bear. Upon the death of Ralph Muller, David recruited Simon Hay who had guest edited two volumes already, onto the editorial board who served for 8 years before handing over to Russell Stothard.

Simon I. Hay (2006 - 2014, Volumes 65-81) served as co-editor while based at the University of Oxford within the Department of Zoology. His interests were focused on spatial and temporal epidemiology of infectious diseases, especially malaria, and he had been an invited guest editor of Advances in Parasitology on two previous occasions. During his time as co-editor, Simon accumulated many awards and honours, the Scientific Medal (2008) of the Zoological Society of London and the Back Award (2012) of the Royal Geographical Society for research contributing to public health policy. He has also received the Bailey K. Ashford Medal (2013) of the American Society of Tropical Medicine and Hygiene and the Chalmers Memorial Medal (2015) of the Royal Society of Tropical Medicine and Hygiene, both for contributions to tropical medicine. He later joined the University of Washington to become Director of Geospatial Science at the Institute for Health Metrics and Evaluation (IHME) and resigned editorial duties from Advances in Parasitology although remains on its editorial board. Simon now leads an international collaboration of researchers, from a wide variety of academic disciplines, with the objective of improving the outputs and outcomes of infectious disease cartography.

J. Russell Stothard (2014 - present, Volumes $85-100$ ) was invited to the editorial team while Professor of Medical Parasitology at the Liverpool School of Tropical Medicine. Russell is also Director of COUNTDOWN, an implementation research consortium funded by the UK Department for International Development focused on the control of neglected tropical diseases. Russell is interested in the epidemiology and control of schistosomiasis, soiltransmitted helminthiasis and malaria. He completed his PhD at Imperial College London in 1995 under the supervision of David Rollinson. Russell also worked at the London School of Hygiene and Tropical Medicine on the molecular biology of the Kinetoplastida and also worked in many sub-Saharan African countries to assist their national disease control 
programmes. Over the years, he has regularly provided advice to WHO. In recognition of his work on Zanzibar, he was awarded the Bicentenary Medal of the Linnean Society in 2004 and has served as Honorary Scientific Secretary of the Royal Society of Tropical Medicine and Hygiene and General Secretary of the British Society for Parasitology. Russell has also co-edited four special issues of Parasitology, Control of schistosomiasis in sub-Saharan Africa (2009), Progress in paediatric parasitology (2011), Advances in diagnostics for parasitic diseases (2014) and Multidisciplinarity of parasitological research (2018). Upon the passing of John Baker, he gratefully received John's collection of parasitological text books, inclusive of all his treasured volumes of Advances in Parasitology, 76 in total. Russell is active in parasitological teaching and is Programme Director of the University of Liverpool's Tropical Disease Biology undergraduate degree programme.

\subsection{Synopsis of production}

Beginning in 1963 with production of the first volume, Advances in Parasitology was produced volume for volume year on year with between 4-6 commissioned articles which followed a long format review style, some 20,000 words each in total, and in an eclectic collection of topics. In certain years, for example 1968, 1970 and 1973, the number of articles peaked reaching 11,9 and 13 respectively, partly due to the introduction of shortreview format articles, approximately 5,000 words in length. The long format review model of production was more popular and largely continued unperturbed until 1994 when general production of the journal was stepped up to two volumes a year. After David Rollinson brought new ideas to the team, such as the introduction of a relevant cover picture to highlight a key paper within each volume, albeit eclectic or later thematic, and introduction of thematic volumes. The latter is a collection of papers grouped by a single topic or umbrella theme and guest edited by an editorial or small editorial team. From 1998 onwards, production sometimes peaked to three volumes per year and the list of thematic volumes and guest editors is provided here.

Tzipori, S. (ed). Opportunistic Protozoa in Humans. (1998). Advances in Parasitology, 40, 1-419.

Hay, S.I., Randolph, S.E. \& Rogers, D.J. (eds.). Remote Sensing and Geograpical Information Systems in Epidemiology. (2000). Advances in Parasitology, 47, 1-353. 
Littlewood, D.T.J. (ed.). The Evolution of Parastisim: A Phylogenetic Perspective. (2003). Advances in Parasitology, 54, 1-399.

Molyneux, D.H. (ed.). Control of Human Parasitic Diseases. (2006). Advances in Parasitology, 61, 1 655.

Hay, S. I., Graham, A. \& Rogers, D. J. (eds.) Global Mapping of Infectious Diseases: Methods, Examples and Emerging Applications. (2006). Advances in Parasitology, 62, 1- 391.

Sherman, I.W. (ed) Reflections on a Century of Malaria Biochemistry. (2009). Advances in Parasitology, 67, 1-403.

Webster, J.P (ed.) Natural History of Host-Parasite Interactions. (2009). Advances in Parasitology, 68, 1-337.

Prevost, G. (ed.). Parasitoids of Drosophila. (2009). Advances in Parasitology, 70, 1-373.

Zhou, X. N., Bergquist, R., Oleveda, R. \& Utzinger, J. (eds.) Important Helminth Infections in Southeast Asia: Diversity and Potential for Control and Elimination, Pt A. (2010). Advances in Parasitology, 72, 1-455.

Zhou, X. N., Bergquist, R., Oleveda, R. \& Utzinger, J. (eds.) Important Helminth Infections in Southeast Asia: Diversity and Potential for Control and Elimination, Pt B. (2010). Advances in Parasitology, 73, 1-462.

Weiss, L.M. \& Tanowitz, H.B. (eds.) Chagas Disease, Part B. (2011). Advances in Parasitology, 75, 1344.

Hay, S. I., Price, R. \& Baird, J. K. (eds.) Epidemiology of Plasmodium vivax: History, Hiatus and Hubris, Pt A. (2012). Advances in Parasitology, 80, 1-341.

Hay, S. I., Price, R. \& Baird, J. K. (eds.) Epidemiology of Plasmodium vivax: History, Hiatus and Hubris, Pt B. (2013). Advances in Parasitology, 81, 1-255.

Zhou, X. N., Kramer, R. \& Yang, W. Z. (eds.) Malaria Control and Elimination Program in the People's Republic of China. (2014). Advances in Parasitology, 86, 1-337.

Anderson, R. M. \& Basanez, M. G. (eds.) Mathematical Models for Neglected Tropical Diseases: Essential Tools for Control and Elimination, Pt A. (2015). Advances in Parastiology, 87, 1-445.

Debaets, K. \& Littlewood, D. T. J. (eds.) Fossil Parasites. (2015). Advances in Parastiology, 90, 1-420.

Anderson, R. M. \& Basanez, M. G. (eds.) Mathematical Models for Neglected Tropical Diseases: Essential Tools for Control and Elimination, Pt B. (2016). Advances in Parastiology, 94, 1-434.

Gasser, R. B. \& Von Samson-Himmelstjerna, G. (eds.) Haemonchus contortus and Haemonchosis: Past, Present and Future Trends. (2016). Advances in Parastiology, 93, 1-666.

Zhou, X. N., Lil, S. Z., Utzinger, J. \& Bergquist, R. (eds.) Schistosomiasis in the People's Republic of China: From Control to Elimination. (2016). Advances in Parastiology, 92, 1-501. 
Thompson, R. C. A., Deplazes, P. \& Lymbery, A. J. (eds.) Echinococcus and Echinococcosis, Pt A. (2017) Advances in Parastiology, 95, 1-525.

With the growing list of thematic issues, some of which needed two parts to cover their chosen topic in sufficient detail, this success has given a greater international flavour to the journal, involving researchers from Australia and China and better gender balance to the editorial team. From this growing interest, Elsevier agreed to increase production of Advances in Parasitology to four volumes per year from 2014, and offer print on demand when needed. This has proven successful, and while the balance between eclectic and thematic volumes is expected to be approximately even, it provides some flexibility to react to demand. For example, the thematic format has significant appeal and can cater for a very in-depth appraisal, especially if there is sufficient content for a part A and B structure.

The total number of review articles through time is shown in Figure 1, which also compares the number of primarily research articles in production of the Cambridge University Press Parasitology, which is typically produced monthly with 8-12 papers in each issue. Parasitology has a focus on manuscripts containing primary data but short format reviews are also popular within special issues produced twice a year. As might be expected there is a lot of cross-citation between Advances in Parasitology and Parasitology as primary research is consolidated into reviews and reviews help spring board primary research. There is of course fluctuations in the number of articles, peaking in 2016 for Advances in Parasitology, largely due to the production of 3 thematic volumes that year. It is interesting to note some features are shared across the two journals, in particular there are dips in production in 2002 and 2008 which may be due to referencing or curation errors of the Web of Knowledge database largely due to automated data capture techniques (see below).

<please insert Figure 1 here>

\subsection{Reflections on content}

It is beyond the scope of the current review to provide an exact analysis of all contents of Advances in Parasitology through time but it is worth noting that the simple distinctions between medical, veterinary and wildlife parasitological groupings has merit in an attempt to do so. Further classification of sub-disciplines, themes and topics can become more 
confusing as articles may or may not fit well, or not exclusively, within each as, for example, molecular methods or analytical tools often cross the boundaries between helminth and protist even within each of these three groupings. Nonetheless, it is useful to make a cursory examination of the content of the most popular papers, as judged by the most citations accumulated during the life of this Series, see Table 1, as well as within the last decade, see Table 2.

The paper with the most citations (Anderson and May, 1985) is a treatise on the population biology of parasites, mainly soil-transmitted nematodes but has scope to crosstalk or be placed within each of medical, veterinary and wildlife categories. The paper by (Hall and Wall, 1995) is a good example of the broader and inclusive forum of Advances in Parasitology; a welcomed inclusion of the study of dipteran larvae that cause myiasis, largely in farmed livestock. Across the other papers, the balance between helminth and protist is broadly similar but immunological studies on helminthiasis dominate. These patterns have changed in the last decade, perhaps as immunological studies subside and are replaced by molecular DNA and epidemiological studies. The later approaches have benefited from introduction and expansion of new laboratory techniques with a supporting commercial industry within the life sciences; there is certainly much better computing power, larger data sets and more affordable surveillance technologies. However, studies on helminths now trend and dominate, which is a surprise given the global attention of malaria, with a human genetic perspective, G6PD deficiency associated with malaria, now attracting significant interest in this sector. For helminthiasis, of particular note are the papers on Fasciola (Mas-Coma et al., 2009) and Anisakis (Mattiucci and Nascetti, 2008) which have attracted sufficient attention in the last decade to also feature in the top ten list of most cited papers in general. As might be expected, none of the most cited papers appearing in Tables $1 \& 2$ were produced in the first or fiftieth volumes but it is still worth making a qualitative appraisal of the contents of these volumes. This might signpost more pertinent changes in parasitology between 1963 and 2000, a period of just under forty years, largely commensurate with an academic research career.

<please insert Table 1 \& Table 2 here>

\subsection{Volume 1}


Of the 6 chapters within the first edition, there is a strong theme of agricultural disease and production of farmed animals and crop plants. For example, coccidiosis in domestic fowl and the turkey is considered by Horton-Smith and Long, then based at the Houghton Poultry Research Station, Huntingdon, UK (Horton-Smith and Long, 1963); parasitic bronchitis in cattle was discussed by Poynter from the Parasitology Department, Allen and Hanbury's Ltd, Ware, UK (Poynter, 1963); the biology of infective stages of nematodes in plants and animals was assessed by Rogers and Sommerville from the University of Adelaide, Australia and McMaster Laboratory, C.S.I.R.O., Glebe, Australia (Rogers and Sommerville, 1963). Each of these articles has a strong applied perspective while the other articles by Huff on experimental research on avian malaria, when based at the Naval Medical Research Institute, Bethesda, USA, as well as the treatise on experimental trichiniasis by Larsh from the School of Public Health, Duke University, USA, have more medical context. The article by Llewellyn, from the University of Birmingham, UK provides a classic taxonomic and morphological appraisal of larvae and larval stages within the Monogenea (Llewellyn, 1963).

As a collection, this volume is eclectic not only in topic and discipline but also in origin of authors. It is clearly international, striking a balance between USA and UK, with Australian authors also featuring. From today's perspective, some features are worthy of note. It must have been hard to assemble and have collated such long international manuscripts with the tools of communication then used. Most likely, all communications would be hand written or produced by type writer, and dependant on airmail. The latter would still have had delays of several days or weeks between interactions and been costly, notwithstanding use of colour plates. Interestingly, there was then a much greater interest in the practice of agricultural zoology viz. parasitology, and institutions engaged in animal health and increasing food production, were perhaps more common. Things have changed extensively, for example, Allen and Hanburys Ltd, a small pharmaceutical firm founded in 1715, was later absorbed by Glaxo Laboratories (now GlaxoSminthKline) but continued to use Allen and Hanburys name for their specialist respiratory division until phased out in 2013. GlaxoSmithKline is of course still active in pharmaceutical donation of albendazole for control of filarial nematodes in humans, although divested its animal health business in the 1990s. Parasitic diseases of livestock continue to cause significant economic losses, especially in the face of increasing resistance to the older anthelminthics but, even with 
increasing demand in the pet market, the cost of developing profitable new products (be these new chemical entities or vaccines) for animal health is challenging. On the other hand, Horton-Smith and Long's article is prophetic for it introduced molecular methods of characterisation of parasites using DNA, RNA and isoenzymes methods, as well as other biomarkers, which were to become the backbone technology of life sciences as molecular biological methods became routine and commercialised.

\subsection{Volume 50}

The illustrated front cover of volume 50 provides a striking example of the change of format and production (the $3^{\text {rd }}$ volume in 2000), but remained in eclectic format. Here the presence of the desktop computer is now apparent and an ability for authors to indulge in desktop publishing technology and imagery either factual or artistic. Furthermore, the photomicrograph of expression of reporter genes in transgenic Caenorhabditis elegans under the control of the Haemonchus contortus pepsinogen promoter is a strong echo of Horton-Smith and Long's foray into molecular parasitology with the methods now widely available in the life sciences. The comparison through time here is very clear, the decline of agricultural focused work and the rise in molecular methods in parasitological research, with the growth of computational data analysis as computers and analytical software became more sophisticated.

The 4 chapters of volume 50 can be set against those of volume 1; they all have incorporated molecular and epidemiological evidence into their appraisals, while authors are still based in the USA, UK and Australia. The first chapter, the biochemical and molecular features of malaria-infected red blood cells was reviewed by Cooke, Mohandas and Coppel and shows the growing interest in molecular pathogenesis of Plasmodium (Cooke et al., 2001) and has accumulated 147 citations so far. Such studies on malaria were boosted greatly by the ability to produce human Plasmodium parasites in cell culture, pioneered in the 1970s (Trager and Jensen, 1976), rather than in experimental models, so diminishing the need for avian models (Huff, 1963). Nonetheless, Huff's article still attracted 17 citations in total, the most recent of which was in 2015 (Mac-Daniel and Menard, 2015), and studies on PfEMP1 proteins are vibrant and still feature in Advances in Parasitology (Hviid and Jensen, 2015). Indeed, Hviid and Jensen's review already has 24 citations, averaging just over 7 each year. 
Other chapters have a concurrent theme of molecular evidence. For example, using molecular phylogenetic approaches, Attwood was able to piece together and reconstruct a convincing evolutionary history and colonisation patterns of Schistosoma mekongi and its neotriculine intermediate host snails (Attwood, 2001). Further biochemical and molecular aspects of the sexual biology of nematodes and schistosomes were discussed by Boag, Newton and Gasser (Boag et al., 2001). This topic has further expanded in recent years as the genomes of these parasites have been fully characterised with modern sequencing methods and poly'omic approaches. The final chapter by Tagboto and Townson followed in the eclectic tradition and was a pharmacological perspective on medicinal and naturally occurring products that have antiparasitic action (Tagboto and Townson, 2001). This review has attracted 120 citations within a diverse list of journals outside the field of parasitology.

In comparing volumes 1 and 50 with the $100^{\text {th }}$ volume of Advances in Parasitology, it is not surprising that the tradition of USA, UK and Australian based authors has continued but authorship is now much wider and more diverse, notably from China. From this cursory appraisal, some of the changing patterns through time have been identified which allows us now to consider and speculate on what of the future for Advances in Parasitology?

\section{Does parasitology still need Advances in Parasitology?}

Given the growing number of active parasitological researchers across the world, the bourgeoning nature of new techniques used to study parasites, the changing landscape of academia in both teaching and research, as well as the commercial nature of publishing itself, it should be asked does parasitology still need Advances in Parasitology? Fundamentally, we believe so and conclude in the affirmative. However, we also acknowledge the pros and cons within each of the above to contextualise a more subtle and complex set of answers. For simplicity, it might be better to rephrase the question by postulating what might the implications be now or in the future if Advances in Parasitology simply ceased in production?

In line with its the founding rationale, Advances in Parasitology was to provide authentic, well-documented reviews by leading experts in their chosen topic. This was to help others understand recent progress being made across the broader field of parasitology and to influence their research, as well as others in part, from the knowledge gained. A major role of Advances in Parasitology was to disseminate up-to-date information and 
opinions appropriate for university teaching that fostered parasitological research in general. It is notable that Advances in Parasitology was first published one year after the formation of the British Society for Parasitology (BSP see http://bsp.uk.net/) in 1962 (Phillips, 2009b). From then on, Advances in Parasitology was produced once a year typically featuring with 2-6 manuscripts until 1994 when production was increased to two volumes a year.

Unlike the Cambridge University Press journal Parasitology that was first produced in 1908 (Phillips, 2009a) during a period of the 'golden age' of parasitology (Cox, 2017), Advances in Parasitology did not forge close links with the BSP nor affiliated itself formally with any other parasitological society. Nevertheless, all editors of Advances in Parasitology were or are active BSP members as well as the World Federation of Parasitologists (WFP see http://www.wfpnet.org/). Whilst Parasitology is an academic journal chiefly engaged in reporting primary research, it did and still does produce special issues or supplements devoted to specialist topics in review-like formats (Chappell, 2009). To some, this overlap in style and content might be of concern; there is also a growing list of newly created parasitological-focused journals, mainly following the open access publishing model, including BMC's Parasites \& Vectors (Arme, 2008) and Elsevier's Parasite Epidemiology and Control (Kurtzhals and Cowman, 2016). None of these, however, has an identical role to Advances in Parasitology, which remains at the forefront of publishing high-quality in-depth review papers.

< Please insert Figure 3 and 4 near here >

A simple bibliometric analysis using Web of Knowledge reveals that of the 539 articles (note the database has a deficiency of 128 articles and absence of electronic information for 1965-1980 period) published in Advances in Parasitology, there have been 24,804 cumulative citations (and a total of 24,160 citations without self-citations). Of course, some manuscripts are of wider interest than others and have had increased citations. The top 10 most cited articles are detailed (see Table 1 ) and these 10 articles (Alexander, 1992, Alvar et al., 2004, Anderson and May, 1985, Brooker et al., 2006, Butterworth, 1984, Hall and Wall, 1995, Liew and Odonnell, 1993, Mas-Coma et al., 2009, Mattiucci and Nascetti, 2008, Mehlhorn and Schein, 1984) have had an impressive level of 
scientific attention and dissemination. This interest shows little sign of diminishing over the next decade, as seen in the upward citation trends through time (see Figure 3). Also of note is the journal's h-index of 91, meaning there are 91 articles that have been cited 91 times or more.

In comparison with all other articles within Advances in Parasitology, the average number of citations per published article is 46 . Within the last decade, more current trends are evident (see Figure 4) with Mas-Coma, Valero \& Bargues (2009) and Mattiucci \& Nascetti (2008) cited 232 and 217 times, with an average number of citations per year of 23.2. and 19.8, respectively (see Table 2). The increase in article citations from 2005 onwards is likely a general consequence in the growing accessibility of scientific articles through the world wide web and(or) better online databases, article searching and manuscript retrieval. It can therefore be safely concluded that even if Advances in Parasitology ceased, there would be an enduring legacy and electronic footprint within academic literature for years to come, notwithstanding reference to the actual hardcopies in libraries and personal offices.

With the increasing impact and uptake of Advances in Parasitology, it was decided from 2017 that there was both sufficient scope, demand and financing to produce four volumes a year, in a quarterly manner. Each volume typically has between 4-6 chapters, usually of 20,000 words in length, and can be eclectic in format i.e. diverse chapters without a uniting theme, or thematic in format i.e. chapters united within an umbrella or common theme. The more in-depth nature of Advances in Parasitology articles and the fact that authors are typically commissioned by invitation (although open submissions may be welcomed if appropriate), also sets this Series apart from other scientific journals. The clear success of thematic volumes such as Fossil Parasites (2015a), Mathematical Modelling part A and B (2015b), Asian Schistosomiasis (2016b) and Haemonchosis part A and B (2016a) has shown that there is interest and commitment to produce comprehensive volumes devoted to specific themes which are not covered in sufficient detail in standard parasitological textbooks e.g. Parasitology: An Integrated Approach (Gunn and Pitt, 2012) or Parasitology: A Conceptual Approach (Loker and Hofkin, 2015) or in the special issue or supplemental outlets of other journals. Nonetheless, the only other academic journal that has some overlap with the review-based nature of Advances in Parasitology is Elsevier's Trends in Parasitology, although its production is monthly, has shorter articles and does not have 
regular thematic issues. Taken as a whole, if production of Advances in Parasitology ceased it would create a void that could only be partially filled if other allied journals were able to realign their submission and production systems accordingly.

\section{Outlook}

Academic interests, market forces and financial pressures aside, it is clear that the discipline of parasitology is vibrant, strong and expanding. This is partly so as parasitologists have been able to sustain academic careers and are often excellent in adopting new methods and applying them in new ways to provide fresh insights into the biology of parasites and parasitism in general. It is clear, however, that classic parasitology shaped within morphological and taxonomic methods is very much on the wane; there are fewer and fewer practicing experts, which is a regrettable trend. However, the ethos of Advances in Parasitology is not to force or coerce topics but rather to move forward in a similar fashion as parasitology and parasitologists do themselves. It is therefore important that parasitology and parasitologists continue to embrace and respond to the current problems of human and animal health caused by parasites and not isolate themselves either from the importance of parasites in wildlife, especially where these have zoonotic potential. This broader insight into the general ecology of all life on this planet is wise, especially being cognisant of the role that mankind has in using our finite resources either prudently or recklessly. We hope Advances in Parasitology plays a future more pivotal role in guiding the former and by education mitigates the latter.

To close this celebration of 100 volumes, a quotation from Sir Peter Medawar on the wider ethos of science is apt "scientists are people of very dissimilar temperaments doing different things in very different ways. Among scientists are collectors, classifiers, and compulsive tidiers-up; many are detectives by temperament and many are explorers; some are artists and others artisans". It is very clear that Advances in Parasitology has accomplished and is accomplishing a very important role in advancing the discipline of parasitology by encouraging authors to review in detail fascinating topics concerning the biology and impact of their favourite parasites and vectors. 


\section{Acknowledgements}

Both JRS and DR would like to express their sincere thanks to the production team of Elsevier, all contributing authors and especially to all who have read and acted upon the information conveyed in Advances in Parasitology.

\section{References}

2015a. Fossil parasites. In: DEBAETS, K. \& LITTLEWOOD, D. T. J. (eds.) Fossil parasites.

2015b. Mathematical models for neglected tropical diseases: essential tools for control and elimination, Pt A. In: ANDERSON, R. M. \& BASANEZ, M. G. (eds.) Mathematical models for neglected tropical diseases: essential tools for control and elimination, Pt A.

2016a. Haemonchus contortus and haemonchosis - Past, Present and Future Trends. In: GASSER, R. B. \& VON SAMSON, H. G. (eds.) Haemonchus contortus and haemonchosis - Past, Present and Future Trends.

2016b. Schistosomiasis in The People's Republic of China: From control to elimination. In: ZHOU, X. N., LI, S. Z., UTZINGER, J. \& BERGQUIST, R. (eds.) Schistosomiasis in the People's Republic of China: From control to elimination.

ALEXANDER, J. 1992. The interaction of Leishmania species with macrophages. Advances in Parasitology, 31, 175-254.

ALVAR, J., CANAVATE, C., MOLINA, R., MORENO, J. \& NIETO, J. 2004. Canine leishmaniasis. Advances in Parasitology, Vol 57, 57, 1-88.

ANDERSON, R. M. \& MAY, R. M. 1985. Helminth infections of humans - mathematical models, populations dynamics and control. Advances in Parasitology, 24, 1-101.

ARME, C. 2008. Welcome to Parasites \& Vectors. Parasites \& Vectors, 1.

ATTWOOD, S. W. 2001. Schistosomiasis in the Mekong region: Epidemiology and phylogeography. Advances in Parasitology, Vol 50, 50, 87-152.

BOAG, P. R., NEWTON, S. E. \& GASSER, R. B. 2001. Molecular aspects of sexual development and reproduction in nematodes and schistosomes. In: BAKER, J. R., MULLER, R. \& ROLLINSON, D. (eds.) Advances in Parasitology, Vol 50.

BOOTH, M. 2018. Climate change and the Neglected Tropical Diseases. Advances in Parasitology, 100.

BROOKER, S., CLEMENTS, A. C. A. \& BUNDY, D. A. P. 2006. Global epidemiology, ecology and control of soil-transmitted helminth infections. In: HAY, S. I., GRAHAM, A. \& ROGERS, D. J. (eds.) Advances in Parasitology, Vol 62: Global Mapping of Infectious Diseases: Methods, Examples and Emerging Applications.

BUNDY, D. A. P. 2018. Child development and deworming: a 35 year perspective from the world bank disease control priorities series. Advances in Parasitology, 100.

BUNDY, D. A. P., DE SILVA, N., HORTON, S., PATTON, G. C., SCHULTZ, L., JAMISON, D. T. \& DIS CONTROL PRIORITIES, C. 2018. Investment in child and adolescent health and development: key messages from Disease Control Priorities, 3rd Edition. Lancet, 391, 687-699.

BUTTERWORTH, A. E. 1984. Cell-mediated damage to helminths. Advances in Parasitology, 23, 143235.

CANDIDO, R. R. F., MORASSUTTI, A. L., GRAEFF-TEIXEIRA, C., ST. PIERRE, T. G. \& JONES, M. K. 2018. Structural and physical properties of schistosome eggs. Advances in Parasitology, 100.

CHAPPELL, L. H. 2009. A brief history of Parasitology Supplements and Special Issues. Parasitology, 136, 1385-1387.

COOKE, B. M., MOHANDAS, N. \& COPPELL, R. L. 2001. The malaria-infected red blood cell: Structural and functional changes. In: BAKER, J. R., MULLER, R. \& ROLLINSON, D. (eds.) Advances in Parasitology, Vol 50. 
COX, F. E. G. 2017. The Golden Age of parasitology-1875-1925: the Scottish contributions. Parasitology, 144, 1567-1581.

DAWES, B. 1963. ADVANCES IN PARASITOLOGY - PREFACE. Advances in Parasitology, 1, R7-R12.

GUNN, A. \& PITT, S. J. 2012. Parasitology An Integrated Approach, Wiley \& Blackwell.

HALL, M. \& WALL, R. 1995. Myiasis of humans and domestic animals. Advances in Parasitology, Vol $35,35,257-334$.

HORTON-SMITH, C. \& LONG, P. L. 1963. Coccidia and coccidiosis in the domestic fowl and turkey. Advances in Parasitology, 1, 67-107.

HOTEZ, P. 2018. Human parasitology and parasitic diseases: heading towards 2050. Advances in Parasitology, 100.

HOTEZ, P. J. 2017. Ten failings in global neglected tropical diseases control. Plos Neglected Tropical Diseases, 11.

HUFF, C. G. 1963. Experimental research on avian malaria. Advances in Parasitology, 1, 1-65.

HVIID, L. \& JENSEN, A. T. 2015. PfEMP1-A Parasite protein family of key importance in Plasmodium falciparum malaria immunity and pathogenesis. In: ROLLINSON, D. \& STOTHARD, J. R. (eds.) Advances in Parasitology, Vol 88.

KURTZHALS, J. \& COWMAN, A. 2016. Editorial, launch of Parasite Epidemiology and Control. Parasite epidemiology and control 1, https://doi.org/10.1016/j.parepi.2015.11.001.

LIEW, F. Y. \& ODONNELL, C. A. 1993. Immunology of leishmaniasis. In: BAKER, J. R. \& MULLER, R. (eds.) Advances in Parasitology, Vol 32.

LLEWELLYN, J. 1963. Larvae and larval devleopment of monogeneans. Advances in Parasitology, 1, 287-326.

LOKER, E. S. \& HOFKIN, B. 2015. Parasitology: A Conceptual Approach, Garland Science, Taylor \& Francis Group.

MAC-DANIEL, L. \& MENARD, R. 2015. Plasmodium and mononuclear phagocytes. Microbial Pathogenesis, 78, 43-51.

MAS-COMA, S., VALERO, M. A. \& BARGUES, M. D. 2009. Fasciola, Lymnaeids and human fascioliasis, with a global overview on disease transmission, epidemiology, evolutionary genetics, molecular epidemiology and control. In: ROLLINSON, D. \& HAY, S. I. (eds.) Advances in Parasitology Vol 69.

MATTIUCCI, S. \& NASCETTI, G. 2008. Advances and trends in the molecular systematics of anisakid nematodes, with implications for their evolutionary ecology and host-parasite coevolutionary processes. In: ROLLINSON, D. \& HAY, S. I. (eds.) Advances in Parasitology, Vol 66.

MEHLHORN, H. \& SCHEIN, E. 1984. The piroplasms: lifecycle and sexual stages. Advances in Parasitology, 23, 37-103.

PHILLIPS, R. S. 2009a. A note on the editors of Parasitology. Parasitology, 136, 1663-1663.

PHILLIPS, S. 2009b. The Centenary of Parasitology 1908-2008 FOREWORD. Parasitology, 136, 13831383.

POYNTER, D. 1963. Parasitic bronchitis. Advances in Parasitology, 1, 179-212.

ROGERS, W. P. \& SOMMERVILLE, R. I. 1963. The infective stage of nematode parasites and its significance in parasitism. Advances in Parasitology, 1, 109-177.

TAGBOTO, S. \& TOWNSON, S. 2001. Antiparasitic properties of medicinal plants and other naturally occurring products. Advances in Parasitology, Vol 50, 50, 199-295.

TRAGER, W. \& JENSEN, J. B. 1976. Human malaria parasites in continous culture. Science, 193, 673675.

TRUJILLO-GONZÁLEZ, A., BECKER, J. A. \& HUTSON, K. A. 2018. Parasite dispersal from the ornamental goldfish trade. Advances in Parasitology, 100.

WANGA, D., YOUNGA, N. D., KORHONENA, P. K., BLOUIN, M. S. \& GASSER, R. B. 2018. Clonorchis sinensis and clonorchiasis: the relevance of exploring genetic variation. Advances in Parasitology. 


\section{Figure Legends}

Figure 1. A comparison of the total number of articles published each year for A) Advances in Parasitology and B) Parasitology during the 1997-2017 period. The 2016 impact factor is also shown for each journal as well as ranking within the 36 academic journals assigned to parasitology category for which Advances in Parasitology has ranked consistently within the first quartile.

A) Total number of publications in Advances in Parasitology for 1997-2017 period, with 2016 impact factor

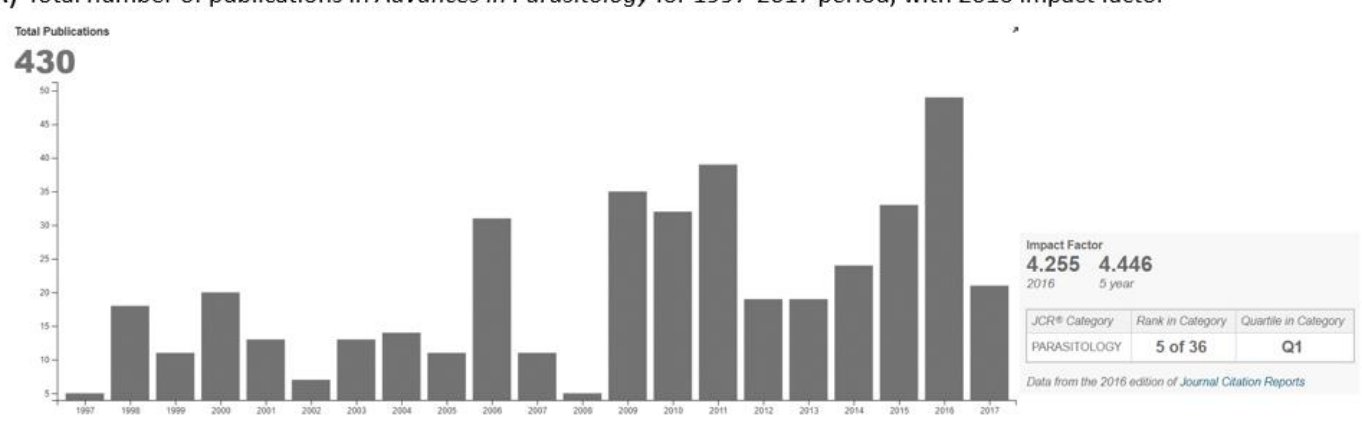

B) Total number of publications in Parasitology for 1997-2017 period, with 2016 impact factor

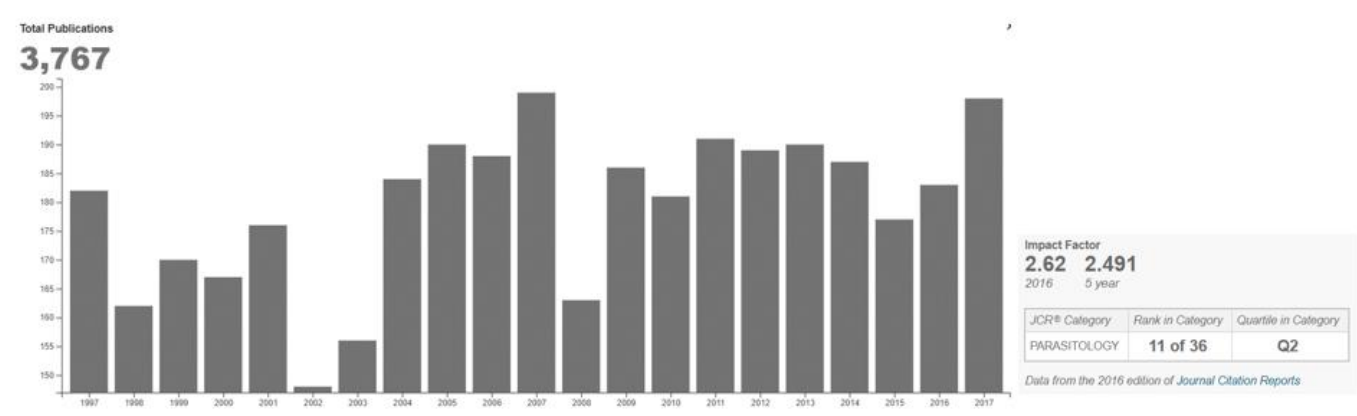


Figure 2. A comparison of the impact factor for Advances in Parasitology and Parasitology during the 1997-2016 period. Note that the fluctuation of the impact factor is related to the number of articles published and cited within the previous 2-year period; the calculation for the 2010 impact factor is highlighted.

An annual impact factor comparison for Advances in Parasitology and Parasitology for the 1997-2016 period

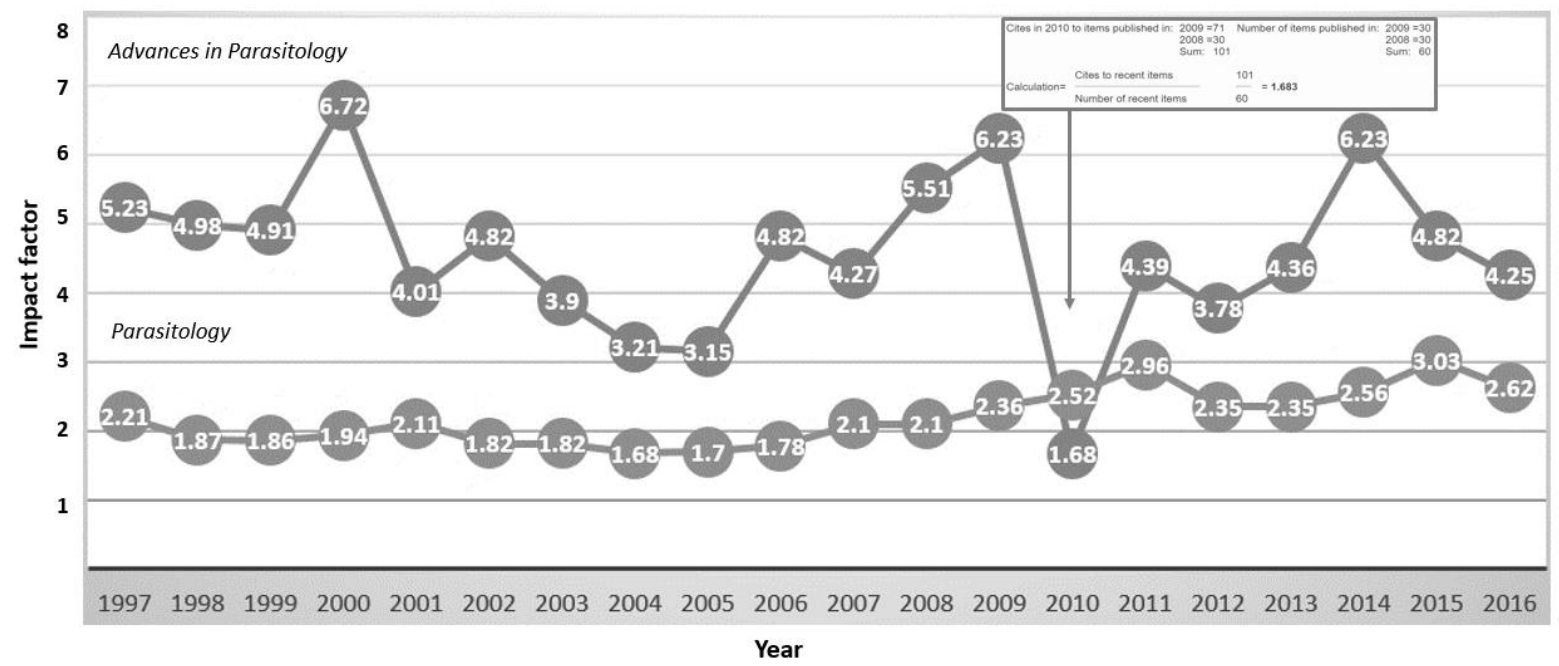


Figure 3. A stacked area chart depicting the annual number of citations for each of the 10 most cited articles in Advances in Parasitology. Although the journal was first published in 1963, only articles published after 1984 start to attain the greatest number of citations with Anderson \& May (1985) having the highest total (see Table 1). There are four features of particular interest, these include peaks in citations in 1998, 2000 and 2009, as well as an increase in citations from 2010 largely due to four papers: Mattiucci and Nascetti (2008), Brooker, Clements and Bundy (2006), Mas-Coma, Valero and Bargues (2009) and Hall and Wall (1995). Within the last decade, the articles by Mas-Coma, Valero and Bargues (2009) and Mattiucci and Nascetti (2008) have generated considerable interest with annual average citations of 23.2 and 19.8, respectively, and no doubt will increase in their order of ranking in subsequent years against the top ten. There is an approximate balance between helminth- and protist-focused articles with the latter having a bias for studies on leishmaniasis.

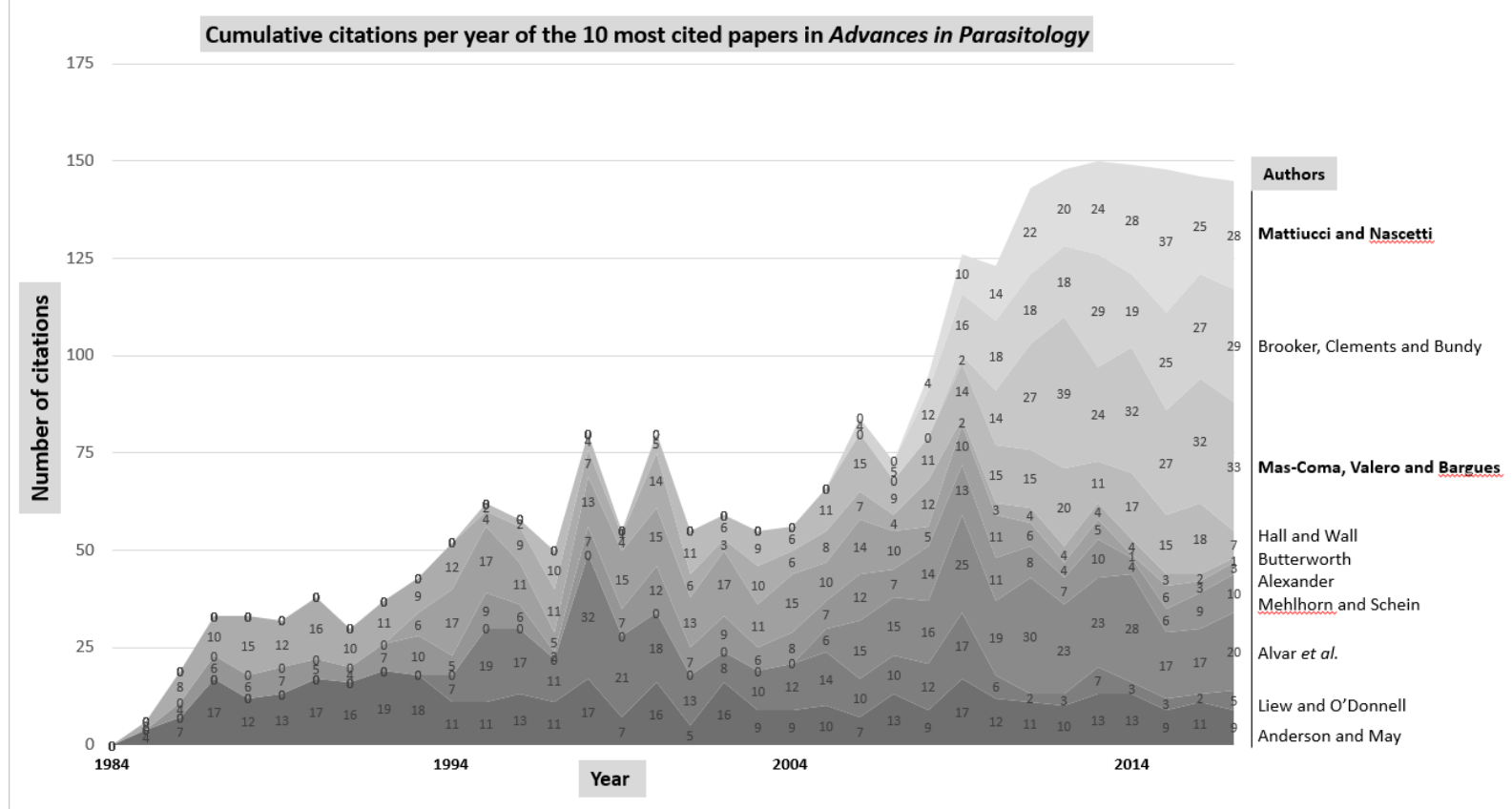


Figure 4. A stacked area chart depicting the annual number of citations for each of the 10 most cited articles in Advances in Parasitology published within the last decade, see Table 2. With the exception of Clark et al. (2010) all articles are consistently receiving 10 or more citations each year. The article by Mas-Coma, Valero and Bargues (2009) has the highest number of total and annual average citation. There is a noticeable dip in citations for all papers in 2013. More generally, helminthfocused articles appear dominant to protist-focused articles and it is worthy of note that human host genetics associated with malaria infection is now featured see Howes et al. (2013) illustrative of the broad remit of Advances in Parasitology to be inclusive of health sciences allied to parasitology.

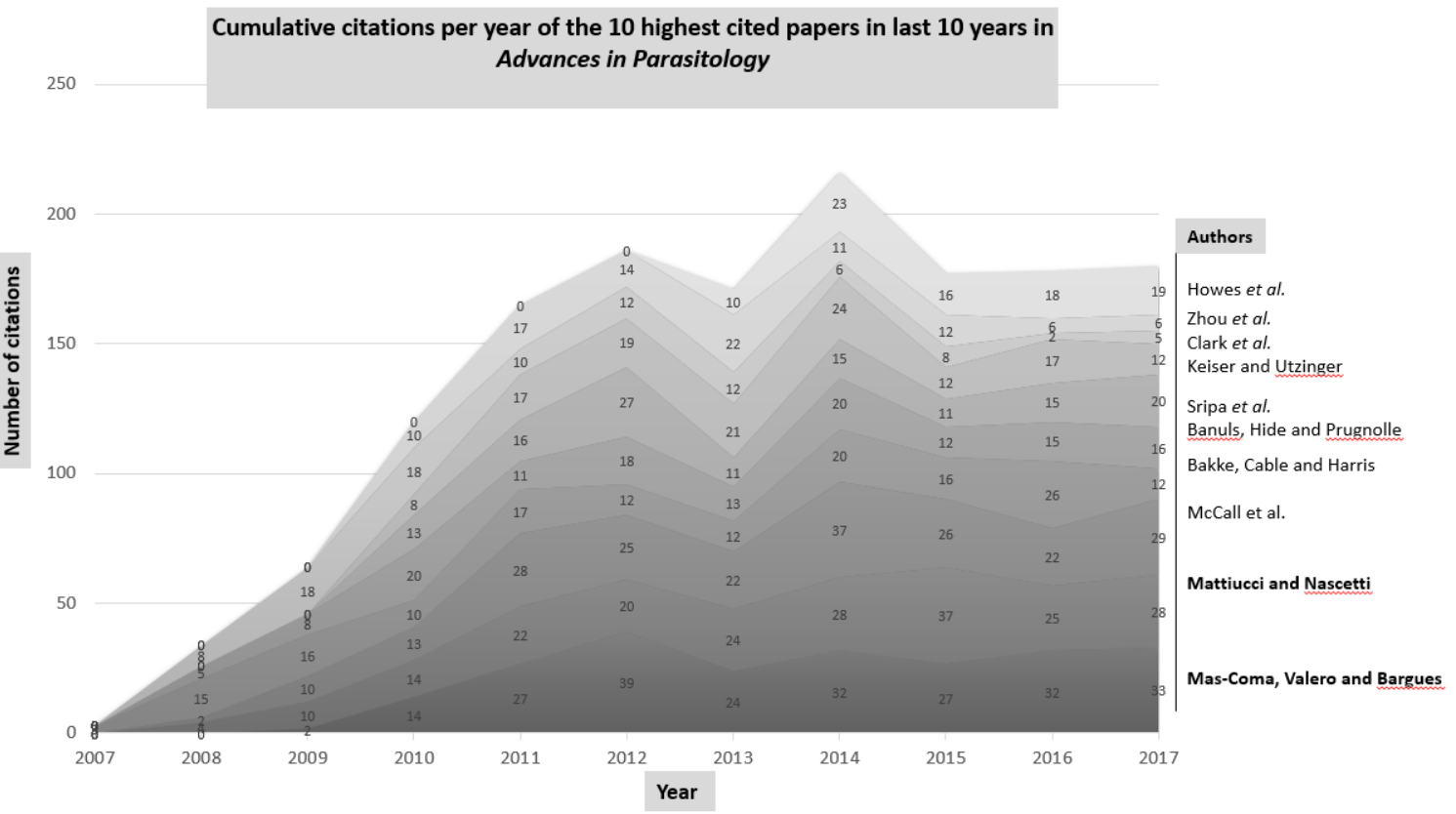


Table 1) The top 10 most cited papers in Advances in Parasitology.

\begin{tabular}{|c|c|c|c|c|}
\hline Authors & $\begin{array}{l}\text { Topic } \\
\text { associated theme (parasite/vector) }\end{array}$ & $\begin{array}{l}\text { Year } \\
\text { published }\end{array}$ & $\begin{array}{l}\text { Total } \\
\text { citations }\end{array}$ & $\begin{array}{l}\text { Average } \\
\text { citations } \\
\text { per year }\end{array}$ \\
\hline Anderson and May & $\begin{array}{l}\text { Population biology } \\
\text { medical, veterinary \& wildlife (helminth) }\end{array}$ & 1985 & 395 & 11.6 \\
\hline Liew and O'Donnell & $\begin{array}{l}\text { Immunology of leishmaniasis } \\
\text { medical (protist) }\end{array}$ & 1993 & 262 & 10.1 \\
\hline Alvar, Canavate, Molina, Moreno and Nieto & $\begin{array}{l}\text { Canine leishmaniasis } \\
\text { medical and veterinory (protist) }\end{array}$ & 2004 & 254 & 17.0 \\
\hline Meblhoro and Schein & $\begin{array}{l}\text { Biology of Piroplasms, } \\
\text { medical, veterinary \& wildlife (protist) }\end{array}$ & 1984 & 246 & 7.0 \\
\hline Alexander & $\begin{array}{l}\text { Immunology of leishmaniasis } \\
\text { medical (protist) }\end{array}$ & 1992 & 243 & 9.0 \\
\hline Butterworth & $\begin{array}{l}\text { Cellular immunology } \\
\text { medical (helminths) }\end{array}$ & 1984 & 237 & 6.7 \\
\hline Hall and Wall & $\begin{array}{l}\text { Myiasis } \\
\text { medical and veterinory (insects) }\end{array}$ & 1995 & 235 & 9.8 \\
\hline Mas-Coma, Valero and Bargues & $\begin{array}{l}\text { Biology and epidemiology fascioliasis } \\
\text { medical, veterinary \& wildlife (helminths) }\end{array}$ & 2009 & 232 & 23.2 \\
\hline Brooker, Clements and Bundy & $\begin{array}{l}\text { Epidemiology of soil-transmitted helminthiasis } \\
\text { medical (helminths) }\end{array}$ & 2006 & 222 & 17.1 \\
\hline Mattiucci and Nascetti & $\begin{array}{l}\text { Evolution and epidemiology of anisakiasis } \\
\text { medical and wildlife (helminths) }\end{array}$ & 2008 & 217 & 19.8 \\
\hline
\end{tabular}


Table 2. Best cited papers in the past 10 years.

\begin{tabular}{|c|c|c|c|c|}
\hline Authors & $\begin{array}{l}\text { Topic } \\
\text { associated theme (parasite/vector) }\end{array}$ & $\begin{array}{l}\text { Year } \\
\text { published }\end{array}$ & $\begin{array}{l}\text { Total } \\
\text { citations }\end{array}$ & $\begin{array}{l}\text { Average } \\
\text { citations } \\
\text { per year }\end{array}$ \\
\hline Mas-Coma, Valero and Bargues & $\begin{array}{l}\text { Biology and epidemiology fascioliasis } \\
\text { medical, veterinary \& wildlife (helminths) }\end{array}$ & 2009 & 232 & 23.2 \\
\hline McCall et ol. & $\begin{array}{l}\text { Heart worm disease } \\
\text { medical and veterinory (helminth) }\end{array}$ & 2008 & 215 & 19.5 \\
\hline Bakke, Cable and Harris & $\begin{array}{l}\text { Biology of gxcodactylids } \\
\text { veterinary \& wildlife (helminth) }\end{array}$ & 2007 & 160 & 13.3 \\
\hline Sripa, Kaewkes, Maleewong and Brindley & $\begin{array}{l}\text { Biology of food borne trematodes } \\
\text { Medical and veterinary (helminths) }\end{array}$ & 2010 & 132 & 14.7 \\
\hline Keiser and Utzinger & $\begin{array}{l}\text { Antiheminthic drugs } \\
\text { medical and veterinory (helminths) }\end{array}$ & 2010 & 131 & 14.6 \\
\hline Clark et al. & $\begin{array}{l}\text { Genome of Entamoebo } \\
\text { medical (protist) }\end{array}$ & 2007 & 99 & 8.3 \\
\hline Zhou et al. & $\begin{array}{l}\text { Epidemiology of Asian schistosomiasis } \\
\text { medical (helminths) }\end{array}$ & 2010 & 98 & 10.9 \\
\hline Howes et al. & $\begin{array}{l}\text { G6PD Deficiency } \\
\text { medical (host genetics associated with malaria) }\end{array}$ & 2013 & 80 & 14.7 \\
\hline
\end{tabular}

